\title{
Changes in pulmonary arterial pressure in preterm infants with chronic lung disease
}

\author{
N V Subhedar, N J Shaw
}

\begin{abstract}
Background-Pulmonary arterial pressure (PAP) is raised in preterm infants with respiratory distress syndrome who subsequently develop chronic lung disease. The natural history of pulmonary hypertension in infants with chronic lung disease is unknown.

Objectives-To investigate changes in PAP, assessed non-invasively using Doppler echocardiography, in infants with chronic lung disease during the 1 st year of life.

Methods-Serial examinations were performed in infants with chronic lung disease and healthy preterm infants. The Doppler derived acceleration time to right ventricular ejection time ratio (AT/RVET) was calculated from measurements made from the pulmonary artery velocity waveform.

Results-A total of 248 examinations were performed in 54 infants with chronic lung disease and 44 healthy preterm infants. The median AT/RVET was significantly lower in infants with chronic lung disease than in healthy preterm infants $(0.31 v$ 0.37). AT/RVET significantly correlated with age corrected for prematurity in both infants with chronic lung disease $(r=0.67)$ and healthy infants $(r=0.55)$. There was no significant difference between the rate of change in AT/RVET between the two groups. In infants with chronic lung disease, multivariate analysis showed that AT/RVET was significantly independently associated with age and inversely with duration of supplemental oxygen treatment. Median AT/RVET was significantly lower in infants with chronic lung disease until 40-52 weeks of age corrected for prematurity.

Conclusions-Although PAP falls with increasing age in both infants with chronic lung disease and healthy preterm infants, it remains persistently raised in infants with chronic lung disease until the end of the 1st year of life.
\end{abstract}

(Arch Dis Child Fetal Neonatal Ed 2000;82:F243-F247)

Neonatal Intensive Care Unit, Liverpool Women's Hospital, Crown Street, Liverpool L8 7 SS, UK

$\mathrm{N} V$ Subhedar N J Shaw

Correspondence to: Dr Subhedar email: n.v.subhedar_lwh $a$ yahoo.com

Accepted 29 September 1999
Keywords: pulmonary arterial pressure; chronic lung disease; Doppler echocardiography; acceleration time to right ventricular ejection time ratio; prematurity

Since Northway et al first described the pathological features of bronchopulmonary dysplasia, ${ }^{1}$ a wide spectrum of cardiorespiratory abnormalities has been recognised. In particular, several abnormalities of structure and function of the pulmonary circulation have been reported. ${ }^{2-6}$
Pulmonary arterial pressure (PAP) is initially raised in infants with respiratory distress syndrome and, in most, gradually declines with improvement in respiratory status. ${ }^{78}$ However, PAP remains persistently raised in infants who subsequently develop chronic lung disease. ${ }^{9}{ }^{10}$ Pulmonary hypertension with raised pulmonary vascular resistance in infants and older children with severe established chronic lung disease has also been demonstrated at cardiac catheterisation in a number of studies, and is associated with a poor prognosis. ${ }^{5611-13}$ The natural history of pulmonary hypertension in infants with established chronic lung disease is unknown.

Pulmonary arterial pressure can be assessed non-invasively by Doppler echocardiography using pulmonary flow indices (and their calculated ratios) measured from the pulmonary artery Doppler velocity waveform. The ratio between the acceleration time (AT) and the right ventricular ejection time (RVET) is inversely related to PAP measured directly at cardiac catheterisation. ${ }^{14}$

The aim of our study was to use this technique to investigate changes in PAP during the 1 st year of life in: (1) healthy preterm infants without respiratory disease, and (2) infants with established chronic lung disease.

\section{Methods}

Infants with chronic lung disease and healthy preterm infants were studied prospectively during a two year period between June 1995 and May 1997. Infants with chronic lung disease, defined as oxygen dependency for at least 28 days and beyond 36 post menstrual weeks in association with an abnormal chest radiograph, were studied at the regional chronic lung disease follow up clinic. Preterm infants without chronic lung disease, who had received mechanical ventilation for less than 24 hours and supplemental oxygen for less than 72 hours were studied as a healthy preterm reference population for comparison. Doppler echocardiographic assessments of PAP were performed at the time that the infants attended for routine follow up.

Pulmonary artery Doppler examination was performed using either a Hewlett Packard Sonos 100 or a Vingmed CFM 725 ultrasound system. A $7.5 \mathrm{MHz}$ multifrequency imaging transducer combined with a $5 \mathrm{MHz}$ Doppler transducer was used with each machine. After a preliminary cross sectional echocardiographic examination to exclude structural defects, a two dimensional image of the main pulmonary artery and pulmonary valve leaflets was obtained from a modified parasternal short axis 
Table 1 Characteristics of study groups

\begin{tabular}{llll}
\hline & $\begin{array}{c}\text { Infants with CLD } \\
(n=54)\end{array}$ & $\begin{array}{l}\text { Healthy preterm } \\
\text { infants }(n=44)\end{array}$ & p Value \\
\hline Birthweight (g) $^{\star}$ & $1055(510-2310)$ & $1420(840-2150)$ & $<0.01$ \\
Gestation (weeks) & $28(24-34)$ & $30(26-34)$ & $<0.01$ \\
Sex (M:F) & $28: 26$ & $23: 21$ & 1.0 \\
Multiple pregnancy (\%) & $10(19)$ & $20(45)$ & $<0.01$ \\
Antenatal steroids (\%) & $45(83)$ & $31(70)$ & 0.25 \\
Caesarean section (\%) & $32(59)$ & $27(61)$ & 1.0 \\
Apgar score at 5 min & $8(3-10)$ & $9(8-10)$ & $<0.01$ \\
Air leak (\%) & $11(20)$ & & \\
Symptomatic PDA (\%) & $5(9)$ & & \\
Total duration of ventilation (days) ${ }^{\star}$ & $16(1-64)$ & & \\
Duration of supplemental oxygen (weeks) & $39(10-103)$ & &
\end{tabular}

*Values expressed as median (range).

CLD, chronic lung disease; PDA, patent ductus arteriosus.

view. Doppler ultrasound examination was performed as described previously. ${ }^{15}$ Briefly, a Doppler signal was recorded from the centre of the main pulmonary artery immediately distal to the valve leaflets. Measurements of AT and RVET were made from the Doppler velocity waveform. Values of each were obtained from a minimum of five consecutive waveforms and the mean AT/RVET ratio calculated. Because there was no significant correlation between mean AT/RVET and R-R interval from the electrocardiograph, calculation of the corrected AT/RVET ratio was considered unnecessary. ${ }^{16}$ Subjective assessment of right ventricular contractility was normal in all patients. Doppler examinations were performed by a single observer (NVS) and infants were studied while asleep or during a period of quiet wakefulness. The intraobserver reproducibility of this technique has been reported previously. ${ }^{15}$

Clinical and demographic data were collected from case notes. All infants who required mechanical ventilation for respiratory distress were treated with two doses of surfactant, immediately after birth and again at 12 hours of age. Symptomatic patent ductus arteriosus was recorded when an infant with a clinical diagnosis of patent ductus arteriosus was treated with indometacin, or underwent surgical ligation. The total number of days of mechanical ventilation while on the neonatal unit, and the total duration of supplemental oxygen treatment were also recorded.

Supplemental oxygen treatment was prescribed to maintain arterial oxygen saturation $\left(\mathrm{SpO}_{2}\right)$ consistently above 93\%, measured using an Ohmeda Biox 3700e pulse oximeter. Oxygen was discontinued when an infant was able to maintain $\mathrm{SpO}_{2}$ values consistently above $93 \%$ during an overnight saturation study. Satisfactory $\mathrm{SpO}_{2}$ values (> 93\%) were ensured throughout the Doppler assessment. All infants had stable oxygen requirements and no intercurrent respiratory illness at the time of study. Our study was approved by the local paediatric ethics committee and informed parental consent was obtained.

All statistical analyses were performed using SPSS for Windows, Release 6.0. Results are presented as median (range). Comparisons between infants with chronic lung disease and healthy preterm infants were carried out using the Mann-Whitney $U$ test for continuous data, and $\chi^{2}$ or Fisher's exact test for categorical data. Serial measurements of AT/RVET were grouped and analysed at the following time periods: 36 weeks post menstrual age; at term; 1-13 weeks, 14-26 weeks, 27-39 weeks, and 40-52 weeks of age corrected for prematurity.

Correlation between changes in AT/RVET and age within individual infants (with and without chronic lung disease) was calculated using analysis of covariance. ${ }^{17}$ The overall rate of change in AT/RVET with time (AT/RVET velocity) was calculated for each infant using the first and last measurements made by using the following formula: change in AT/RVET divided by change in time, multiplied by 100 (and expressed as units/week). Median AT/ RVET velocity was compared in healthy infants and infants with chronic lung disease.

Multiple linear regression analysis was used to determine which factors were independently associated with AT/RVET. Because multiple Doppler examinations had been performed two approaches were used:

(1) Using all the available measurements, with AT/RVET as the dependent variable, the influence of birthweight, gestational age, sex, presence of chronic lung disease, and corrected age as explanatory variables was investigated.

(2) In infants with chronic lung disease, with median AT/RVET as the dependent variable, the influence of birthweight, gestation, duration of ventilation, duration of supplemental oxygen treatment, and median corrected age for each individual was investigated. The median values of AT/ RVET and corrected age were used as summary measures of each variable in the regression model, to allow for multiple measurements in an individual.

\section{Results}

Fifty four infants with chronic lung disease and 44 healthy preterm infants were studied. Table 1 shows the demographic and clinical characteristics of the two groups. Infants with chronic lung disease were significantly lighter and less mature at birth, and had a lower 5 minute Apgar score. A significantly higher proportion of the healthy infants studied were born after a multiple pregnancy.

A total of 248 Doppler examinations were performed: 150 studies in infants with chronic lung disease and 98 studies in healthy infants. Table 2 summarises the timing and results of the examinations performed in each group. The median number of examinations was 2 (range, 2-6) in infants with chronic lung disease and 2 (range, 2-4) in healthy preterm infants. There was no significant difference between the two groups in the overall median corrected age at which the examinations were performed: 12 (range, 38 weeks post menstrual age to 44 weeks) in infants with chronic lung disease versus 13 (range, 38 weeks post menstrual age to 39 weeks) in healthy infants $(\mathrm{p}=0.77)$.

The overall median AT/RVET was significantly lower in infants with chronic lung disease (table 2). Figure 1 shows changes in AT/RVET with time. Median AT/RVET in infants with chronic lung disease tended to be 


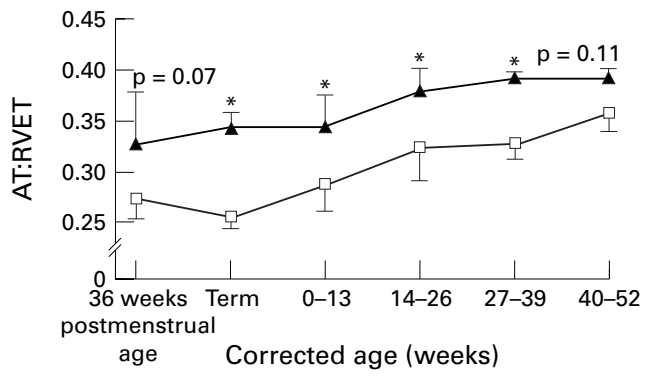

$\Delta$ Healthy preterm infants $\square$ Infants with CLD

Figure 1 Changes in the ratio between acceleration time and the right ventricular ejection time (AT: RVET) with corrected age. Data points are medians (interquartile ranges); $p<0.01$.

lower than that found in healthy infants throughout the period of study. This difference was significant at all time periods except at 36 weeks post menstrual age and between 40 and 52 weeks of age corrected for prematurity.

Within individual healthy preterm infants, changes in AT/RVET were significantly correlated with changes in time $(r=0.67$; $\mathrm{p}<0.001)$. There was a similar degree of correlation between the same variables in infants with chronic lung disease $(r=0.55$; $\mathrm{p}<0.001)$. There was also no significant difference in median AT/RVET velocity between the two groups (table 2).

In the first multiple regression model, AT/RVET was significantly and independently associated with the presence of chronic lung disease, gestational age, and corrected age at examination (table 3 ). In the second multiple regression model, AT/RVET was significantly independently associated with age at examination and inversely with duration of supplemental oxygen treatment in infants with chronic lung disease. The association with gestational age was of borderline significance (table 3 ).

Table 2 Summary of Doppler examinations performed

\begin{tabular}{lll}
\hline & Infants with CLD & Healthy preterm infants \\
\hline Total Doppler examinations & 150 & 98 \\
36 weeks' postmenstrual age & 20 & 19 \\
Term & 16 & 18 \\
$1-13$ weeks & 45 & 18 \\
14-26 weeks & 36 & 15 \\
$27-39$ weeks & 18 & 15 \\
40-52 weeks & 15 & 13 \\
Median AT/RVET & $0.31(0.21 \text { to } 0.43)^{\star}$ & $0.37(0.28$ to 0.43$)$ \\
AT/RVET velocity (units/week) $\ddagger$ & $0.18(-2.7$ to 1.2$) \dagger$ & $0.16(-3.0$ to 3.0$)$ \\
\hline
\end{tabular}

${ }^{*} \mathrm{p}<0.01 ; \mathrm{tp}=0.42$ compared with healthy preterm infants.

$\ddagger$ Values expressed as median (range).

AT/RVET, ratio between acceleration time and the right ventricular ejection time; CLD, chronic lung disease.

Table 3 Multiple regression models

\begin{tabular}{lccl}
\hline Explanatory variable & $b$ & $S E(b)$ & $p$ Value \\
\hline Model 1 with AT/RVET as dependent variable (all infants) & 0.0016 & 0.0002 & $<0.0001$ \\
Age (weeks) & 0.0045 & 0.0014 & 0.002 \\
Gestation (weeks) & -0.0392 & 0.0070 & $<0.0001$ \\
Chronic lung disease (CLD) & 0.0022 & 0.0004 & $<0.0001$ \\
Model 2 with median AT/RVET as dependent variable & (infants with $C L D$ only) & \\
Age (weeks) & -0.0008 & 0.0003 & 0.008 \\
Duration of supplemental oxygen (weeks) & 0.0044 & 0.0022 & 0.057 \\
Gestation (weeks) & &
\end{tabular}

CLD coded as 0 or 1 for healthy infants and infants with CLD, respectively.

b, regression coefficient; SE (b), standard error of regression coefficient.

AT/RVET, ratio between acceleration time and the right ventricular ejection time.

\section{Discussion}

Pulmonary hypertension is common in preterm infants with respiratory distress syndrome and PAP remains raised in those who subsequently develop chronic lung disease. ${ }^{9}{ }^{10} \mathrm{We}$ evaluated changes in PAP, as assessed by the pulmonary artery Doppler derived AT/RVET ratio, in infants with established chronic lung disease and healthy preterm infants after discharge from hospital during the 1 st year of life. Pulmonary arterial pressure is inversely related to age in both healthy infants and those with chronic lung disease. However, although PAP falls at a similar rate during infancy in both groups, infants with established chronic lung disease have persistently raised PAP compared with healthy preterm infants.

In healthy term infants, intra-acinar arterial multiplication parallels alveolar proliferation, which occurs most rapidly in the first 2 years of life. Intra-acinar vessels also increase in size with growth during infancy. ${ }^{18}$ This increase in the total cross sectional area of the pulmonary vascular bed results in an overall reduction in pulmonary vascular resistance. In childhood, this allows PAP to remain unchanged despite an increase in cardiac output. ${ }^{19}$

Lung development in non-ventilated preterm infants is appropriate for post menstrual age, suggesting that preterm birth is not itself associated with poor postnatal lung growth. ${ }^{20}$ In contrast, impaired alveolar and arterial development has been demonstrated in studies of preterm infants dying after mechanical ventilation in the early neonatal period. ${ }^{4}{ }^{20}$ In our study, AT/RVET was significantly directly related to gestational age, indicating that PAP is higher in more immature infants in the 1 st year of life, independently of the presence of chronic lung disease.

Histological studies of the pulmonary circulation in infants and older children dying after the development of chronic lung disease have shown pronounced structural abnormalities, including increased medial thickness of small pulmonary arteries and distal extension of arterial smooth muscle. ${ }^{235}$ There is also a reduction in the number of peripheral arteries associated with a normal alveolar to arterial ratio, indicating failure of alveolar development. ${ }^{4}$ Disruption in growth and development of the pulmonary vascular bed might result in raised pulmonary vascular resistance and PAP in ventilated preterm infants who subsequently develop chronic lung disease.

Several cross sectional echocardiographic studies have described raised PAP in infants with chronic lung disease. ${ }^{21-23}$ Pulmonary hypertension with raised pulmonary vascular resistance has also been confirmed by direct measurement at cardiac catheterisation. ${ }^{6}{ }^{12} 13$ However, the natural history of abnormalities of pulmonary haemodynamics in infants with chronic lung disease is not known. Reports in a few infants who have undergone repeat catheterisation have demonstrated a reduction in PAP with time, although PAP might remain persistently raised into later childhood. ${ }^{64}$ One infant, not receiving supplemental oxygen despite raised PAP, showed progressive pulmo- 
nary hypertension in the 20 month period between catheter investigations. ${ }^{11}$ To our knowledge, there are no published studies of changes in PAP in healthy preterm infants or those with chronic lung disease during infancy after discharge from hospital.

Pulmonary arterial pressure and pulmonary vascular resistance in infants with chronic lung disease have been assessed non-invasively using $M$ mode and Doppler echocardiography. ${ }^{21-23}{ }^{25-27}$ The two methods most commonly used have been: (1) measurement of pulmonary flow indices, or (2) measurement of the maximal velocity of tricuspid regurgitation and application of the modified Bernoulli equation. ${ }^{28}$ Measurement of maximal tricuspid regurgitation velocity is generally accepted as the method of choice when assessing PAP non-invasively. ${ }^{29}$ However, the only study that has used this technique in infants with chronic lung disease found that the incidence of measurable tricuspid regurgitation was only $44 \%$, despite sedation. ${ }^{22}$ The same study also reported a close correlation between measurements of AT/RVET and tricuspid regurgitation derived PAP. Pulmonary flow indices were chosen in our study because measurements could be performed successfully in almost all infants without the need for sedation.

Unlike previous studies, our study has compared PAP in infants with chronic lung disease with healthy preterm infants, rather than using a reference population of preterm infants who had received respiratory support but not developed chronic lung disease. This inevitably led to demographic differences between chronic lung disease infants and our reference group. Although it might have been preferable to have arranged Doppler assessments at predefined times, this was impractical in view of the geographical distribution of the study populations within the Mersey region. Instead, all assessments in our study were made on an opportunistic basis, at the same time as an infant attended follow up clinic. Infants with chronic lung disease who continued to attend clinic throughout the study period are likely to have been the sickest infants. This might have influenced our results through over representation of infants with low AT/RVET values towards the end of our study.

Reactivity of the pulmonary vascular bed to oxygen in infants with chronic lung disease has been confirmed in direct and indirect studies. ${ }^{61322}$ However, the precise relation between different values of $\mathrm{SpO}_{2}$ and PAP has not been fully evaluated. This might reflect the difficulty in maintaining a steady $\mathrm{SpO}_{2}$ value during an echocardiographic examination. Because of the inherent inaccuracy in defining true $\mathrm{SpO}_{2}$ on a background of continuous variation with time and movement artefact, all infants in our study were maintained at $\mathrm{SpO}_{2}$ values above $93 \%$, rather than attempting to define a precise $\mathrm{SpO}_{2}$ value. It is possible that in some infants, maintaining an even higher $\mathrm{SpO}_{2}$ value might have led to a reduction in pulmonary vascular resistance and PAP. ${ }^{22}$

We have shown previously that persistently raised PAP at 24 hours of age is an important early predictor for the development of chronic lung disease in ventilated preterm infants. ${ }^{30}$ Our study has demonstrated an indirectindependent relation between duration of supplemental oxygen treatment and AT/RVET. This suggests that PAP remains higher in infants who receive a longer period of oxygen treatment, and therefore presumably have more severe disease. Because none of our infants died within the period of our study, we were unable to examine the relation between PAP and mortality in our study group.

We have shown that although PAP is higher in infants with chronic lung disease than in healthy preterm infants, it tends to fall with increasing age during the 1 st year of life at a similar rate in both groups. Pulmonary hypertension is also independently associated with a longer duration of supplemental oxygen treatment. Future research will need to consider the importance of pulmonary hypertension and the effects of pulmonary vasodilator treatment in influencing respiratory outcome in preterm infants with chronic lung disease.

NVS was supported by the British Heart Foundation (RF Martin Junior Research Fellowship).

1 Northway WH Jr, Rosan RC, Porter DY. Pulmonary disease following respiratory therapy of hyaline membrane disease: bronchopulmonary dysplasia. N Engl F Med 1967;276:35768.

2 Taghizadeh A, Reynolds EOR. Pathogenesis of bronchopulmonary dysplasia following hyaline membrane disease. $A m$ monary dysplasia followin

3 Tomashefski JF, Oppermann HC, Vawter GF, Reid LM. Bronchopulmonary dysplasia: a morphometric study with emphasis on the pulmonary vasculature. Pediatr Pathol 1984;2:469-87.

4 Hislop AA, Haworth SG. Pulmonary vascular damage and the development of cor pulmonale following hyaline membrane disease. Pediatr Pulmonol 1990;9:152-61.

5 Bush A, Busst CM, Knight WB, Hislop AA, Haworth SG, Shinebourne EA. Changes in pulmonary circulation in severe bronchopulmonary dysplasia. Arch Dis Child 1990;65:739-45.

6 Abman SH, Wolfe RR, Accurso FJ, Koops BL, Bowman M, Wiggins JW. Pulmonary vascular response to oxygen in infants with severe bronchopulmonary dysplasia. Pediatrics $1985 ; 75: 80-4$.

7 Evans NJ, Archer LN. Doppler assessment of pulmonary artery pressure and extrapulmonary shunting in the acute phase of hyaline membrane disease. Arch Dis Child 1991;66:6-11.

8 Evans NJ, Archer LN. Doppler assessment of pulmonary artery pressure during recovery from hyaline membrane disease. Arch Dis Child 1991;66:802-4.

9 Gill AB, Weindling AM. Pulmonary artery pressure changes in the very low birthweight infant developing chronic lung disease. Arch Dis Child 1993;68:303-7.

10 Gill AB, Weindling AM. Raised pulmonary artery pressure in very low birthweight infants requiring supplemental oxygen at 36 weeks after conception. Arch Dis Child Fetal Neonatal Ed 1995;72:F20-2.

11 Harrod JR, L'Heureux P, Wangensteen OD, Hunt CE. Long-term follow-up of severe respiratory distress syndrome treated with IPPB. $\mathcal{F}$ Pediatr 1974;84:277-86.

12 Berman W, Yabek SM, Dillon T, Burstein R, Corlew S. Evaluation of infants with bronchopulmonary dysplasia using cardiac catheterization. Pediatrics 1982;70:70812.

13 Goodman G, Perkin RM, Anas NG, Sperling DR, Hicks DA, Rowen M. Pulmonary hypertension in infants with DA, Rowen M. Pulmonary hypertension in infants with
bronchopulmonary dysplasia. $\mathcal{F}$ Pediatr 1988;112:6772 .

14 Kosturakis D, Goldberg SJ, Allen HD, Loeber C. Doppler echocardiographic prediction of pulmonary arterial hypertension in congenital heart disease. Am $\mathcal{f}$ Cardiol 1984;53:1110-15.

15 Subhedar NV, Shaw NJ. Intraobserver variation in Doppler ultrasound assessment of pulmonary artery pressure. Arch Dis Child Fetal Neonatal Ed 1996;75:F59-61.

16 Akiba T, Yoshikawa M, Otaki S, et al. Prediction of peak pulmonary artery pressure by continuous wave Doppler echocardiography in infants and children. Pediatr Cardiol 1988;9:225-9.

17 Bland JM, Altman DG. Calculating correlation coefficient with repeated observations: correlation within subjects. $B M \mathcal{1}$ 1995;310:446. 
18 Haworth SG, Hislop AA. Pulmonary vascular development: normal values of peripheral vascular structure. Am f Carnormal values of perip.
diol 1983;52:578-83.

19 Haworth SG. Pulmonary vasculature. In: Anderson RH, McCartney FJ, Shinebourne EA, Tynan M, eds. Pediatric cardiology. London: Churchill Livingstone, 1987:123-55.

20 Hislop AA, Wigglesworth JS, Desai R, Aber V. The effects of preterm delivery and mechanical ventilation on human lung growth. Early Hum Dev 1987;15:147-64.

21 Fitzgerald D, Evans N, Van Asperen P, Henderson Smart D. Subclinical persisting pulmonary hypertension in chronic
neonatal lung disease. Arch Dis Child Fetal Neonatal Ed 1994;70:F118-22.

22 Benatar A, Clarke J, Silverman M. Pulmonary hypertension in infants with chronic lung disease: non-invasive evaluation and short term effect of oxygen treatment. Arch Dis Child Fetal Neonatal Ed 1995;72:F14-19.

23 Farstad T, Brockmeier F, Bratlid D. Cardiopulmonary function in premature infants with bronchopulmonary function in premature infants with bronchopulmonary
dysplasia - a 2-year follow up. Eur $\mathcal{f}$ Pediatr 1995;154:8538 .

24 Berman W, Katz R, Yabek SM, Dillon T, Fripp R, Papile L. Long-term follow-up of bronchopulmonary dysplasia. $\mathcal{f}$ Pediatr 1986;109:45-50.
25 Melnick G, Pickoff AS, Ferrer PL, Peyser J, Bancalari E, Gelband $H$. Normal pulmonary vascular resistance and left ventricular hypertrophy in young infants with bronchopulmonary dysplasia: an echocardiographic and pathologic study. Pediatrics 1980;66:589-96.

26 Fouron J, Le Guennec J, Villemant D, Bard H, Perreault G, Davignon A. Value of echocardiography in assessing the outcome of bronchopulmonary dysplasia. Pediatrics 1980;65:529-35.

27 Newth CL, Gow RM, Rowe RD. The assessment of pulmonary arterial pressures in bronchopulmonary dysplasia by cardiac catheterisation and M-mode echocardiography. Pediatr Pulmonol 1985;1:59-63.

28 Yock PG, Popp RL. Noninvasive estimation of right ventricular systolic pressure by Doppler ultrasound in patients with tricuspid regurgitation. Circulation 1984;70:657-62.

29 Zellers T, Gutgesell HP. Noninvasive estimation of pulmonary artery pressure. F Pediatr 1989;114:735-41.

30 Subhedar NV, Hamdan AH, Ryan SW, Shaw NJ. Pulmonary artery pressure: early predictor of chronic lung 1998;78:F20-4 